use in the treatment of chronic conjunctivitis, and "by compression" in cases of chalazion.

The authors hold that " no medicinal treatment is effectual against cataract, but the electrical currents hold out some hope in selected cases." As cataract from electric shock is well known, we suppose that the treatment of cataract by electricity must be undertaken with caution; treatment is said to be prolonged and the results "successful in some incipient cases." In this journal we have expressed our opinion that the "cure of cataract without operation" is an unjustifiable assumption in the present state of our knowledge, and we will leave the subject at that.

The rest of the book does not immediately concern ophthalmic surgeons who practise in this country.

\title{
CORRESPONDENCE
}

\section{PROPTOSIS IN A NEW BORN CHILD}

To the Editor of The British Journal of Ophthalmology

SiR,- With regard to the references to proptosis in the March number of the Brit. Jl. of Ofhthal., p. 141 the following cases should be added to those mentioned.

Berger (Maladies des Yeux, p. 258), quotes a case, seen by Steinheim, in which the ocular muscles were torn by forceps at birth. Purulent keratitis followed with perforation of the cornea. The child died from meningitis in eight days and at the autopsy a fracture of the vault of the orbit was discovered.

Hoffmann is quoted in the same book with respect to an infant delivered by instruments, in which the eye was completely outside the orbit and attached to it only by a fragment. In another case Spaeth, of Vienna, saw a child in which after the use of forceps both eyes were torn.

Fage, of Amiens, refers to a case of Bock's (Central. für prakt. Augenheilk., 1902), in which a face presentation was mistaken for a breech, and the accoucheur passed his finger into the orbit thinking it was the anus, intending to pull the foetus. A dislocated eye resulted followed by panophthalmitis.

In Fage's case the left eye of a female child was completely displaced from the socket after a normal confinement. The day preceding the birth the woman had been struck severely on the lower part of the abdomen by the shaft of a cart. The eye was replaced in the orbit and the lids sewn together. The eye became 
leucomatous but otherwise the result was satisfactory. Dislocation of the eye is known by several names: proptosis, displacement, exophthalmos. Personally I prefer to keep dislocation for cases which are traumatic in origin and proptosis for those associated with myopia, goitre, etc. Exophthalmos is the result.

Yours faithfully,

W. M. Beaumont.

Bath.

\section{OBITUARY}

ALEXANDER DUANE, M.D., D.Sc.

THE fact of Dr. Duane's death was briefly noticed in our pages in Vol. X, and an obituary was promised for some future occasion. The present note is an abstract of the sympathetic notice contained in the Trans. Amer. Ophthal. Soc., Vol. 24, which was contributed by Duane's old friend, John E. Weeks.

Dr. Duane was born in Malone, N.Y. in 1858, the son of General James Duane. He died in New York, of meningitis, on June 10th, 1926.

He was educated at Union College and qualified in Arts in 1878, obtaining his M.D. in 1881. After holding a resident appointment at the New York Hospital, he began to practise in New York City in 1884. Four years later he moved to Norfolk, Virginia, where he stayed for a couple of years and then returned to New York, where he practised for the rest of his life. For many years he was associated with the late Herman Knapp. He was a voluminous writer, and besides some 70 papers contributed to various journals, he supolied the medical terms for Webster's International Iictionary, and those of ophthalmology for Foster's Encyclopaedic Dictionary of Medicine. His Student's Medical Dictionary was published in 1893 , and ran through four editions. His magnum opus was undoubtedly the translation of Fuchs's well-known textbook, which has reached its seventh edition. In 1897, his "Motor Anomalies of the Eye" appeared. Besides all this, he contributed chapters to most of the American ophthalmological textbooks of his time.

Duane served in the Spanish-American War as Lieutenant, U.S.N. and in the Great War as signal officer, U.S.S., "Granite State." He was the author of "Rules for Signalling on Land and Sea" (1899, second edition 1901).

In 1919 he received the honorary degree of D.Sc. from his old college. He became a member of the American Ophthalmological 